DE LA RECHERCHE A L' IND US T R IE
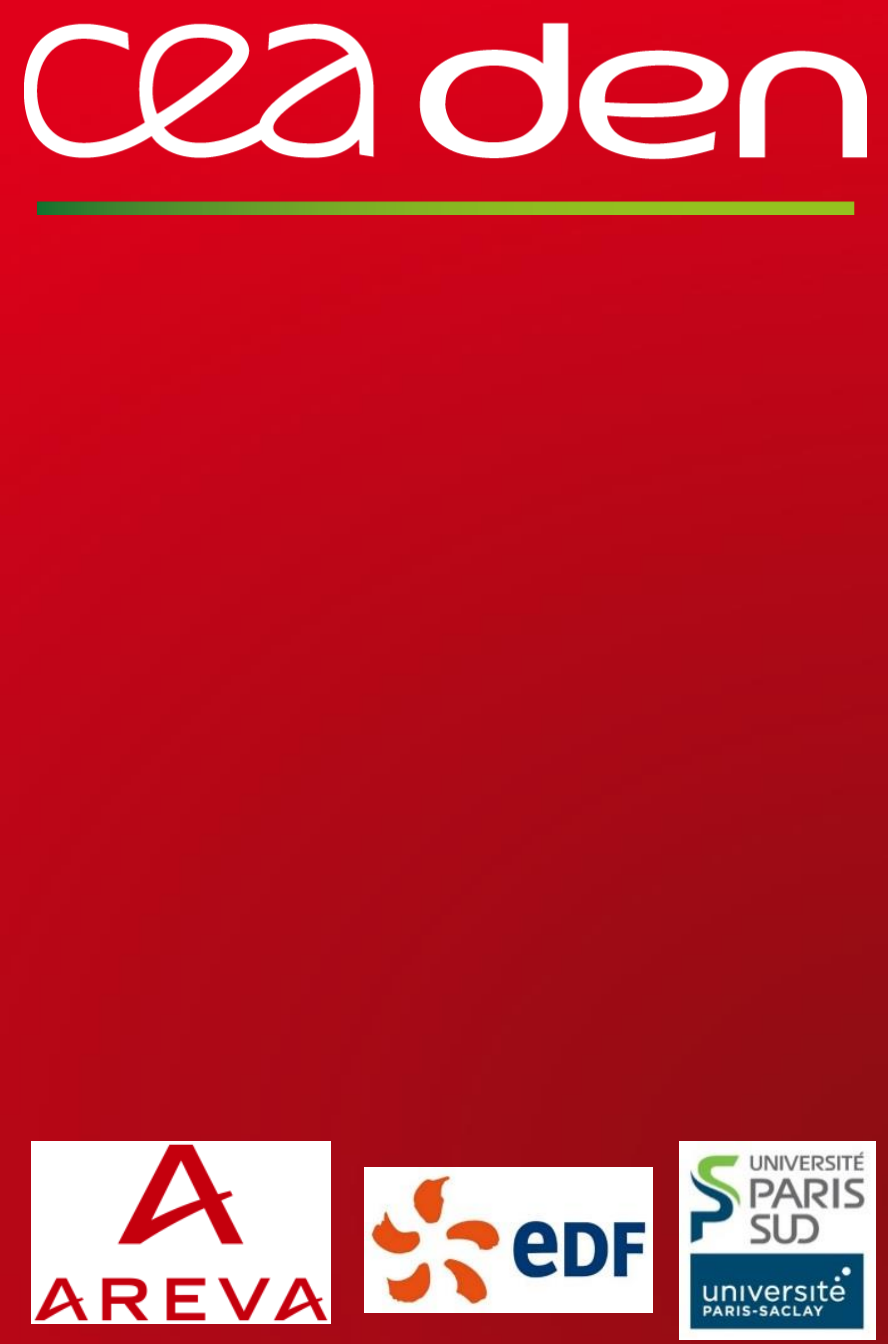

\section{On the radio-oxidation at high doses of an industrial polyesterurethane and its pure resin}

E. Fromentin ${ }^{1}$, C. Aymes-Chodur ${ }^{2}$, D. Doizi ${ }^{1}$, M. Cornaton ${ }^{1}$, F. Miserque ${ }^{3}$, F. Cochin ${ }^{4}$, M. V. di Giandomenico ${ }^{5}$, S. Esnouf ${ }^{1}$, M. Ferry ${ }^{1}$

${ }^{1}$ CEA, DEN, DPC, SECR, LRMO, F-91191 Gif-sur-Yvette, France.

2 Université Paris-Sud, SM2B/ICMMO, UMR CNRS 8182, F-91405, Orsay, France.

${ }^{3}$ CEA, DEN, DPC, SCCME, LECA, F-91191 Gif-sur-Yvette, France.

${ }^{4}$ AREVA NC DOR/RDP, 1 place Jean Millier, F-92084, La Défense Cedex, France.

${ }^{5}$ EDF Lab, Les Renardières, F-77818 Moret-sur-Loing, France. 


\section{ceaden Polymers used in the nuclear industry}

- A wide variety of polymers in the nuclear industry

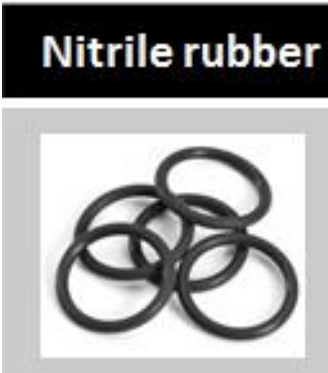
Fluoro elastomer

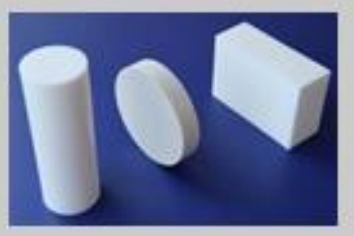

Seals

Seals

\section{Chlorinated polymer}

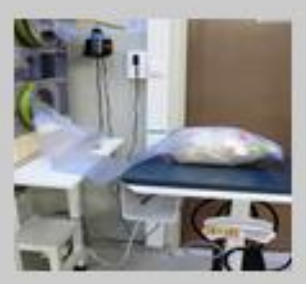

Hot cell sleeve Protection sheet

EPDM

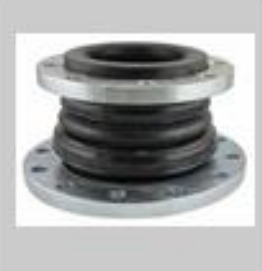

Seals Insulation

\section{Epoxy}

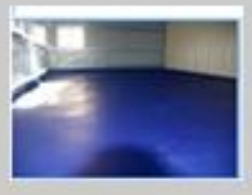

Coating

Paints

\section{Polyurethane}

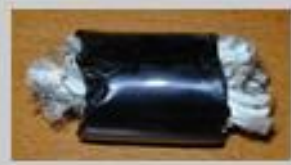

Gloves

Cables sheath Insulation
Acrylic

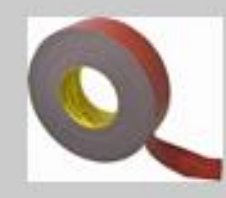

Scotch
Storage and

$\Rightarrow \quad$ then disposal

(future)

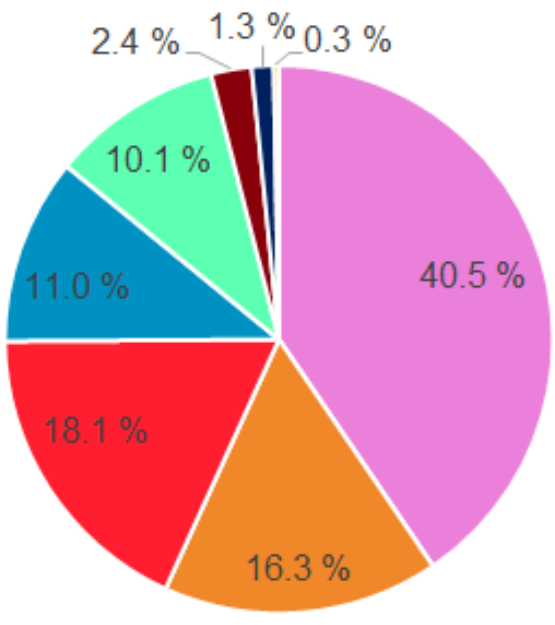

= Chlorinated polymers

- Polyolefins

- Ion exchange resins

- Other

= Cellulose

- Fluorinated polymers

- Polyurethanes

= Polyamide

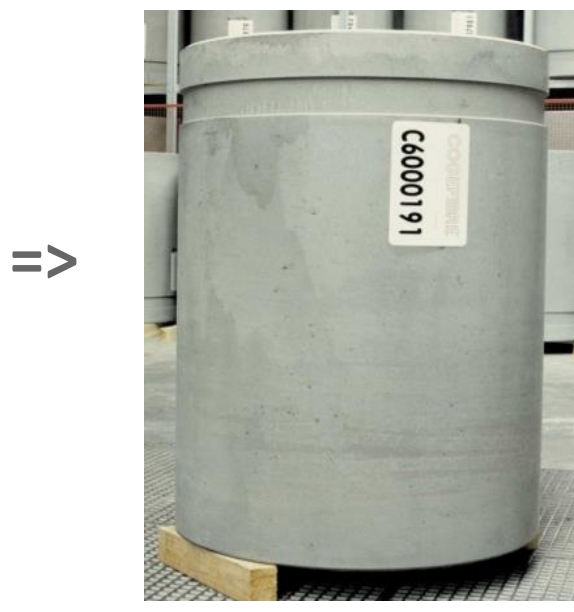

Intermediate Level Long Lived Waste (IL-LLW) 


\section{Polymers in nuclear waste containers}

- Polymers in contact with radionuclides (RN) in the Intermediate Level Long Lived Waste (IL-LLW) packages

Dain risk associated with storage

- Gas emission (inflammation, corrosion...)

Estimate/simulate, over years (up to about 10 MGy), main gases emission

- Necessity to understand the evolution of the different polymers under irradiation

- Identification and as much as possible quantification of the degradation products 


\section{ceaden}

\section{Irradiation conditions}

- Gamma irradiations

- ${ }^{60}$ Co source (about $0.8 \mathrm{kGy} \cdot \mathrm{h}^{-1}$ )

- PURm: 500, 1 000, 4 000, 10000 kGy

- PURe: 500, 1 000, 4000 kGy

- Homogeneous radio-oxidation conditions

- Thickness < critical thickness

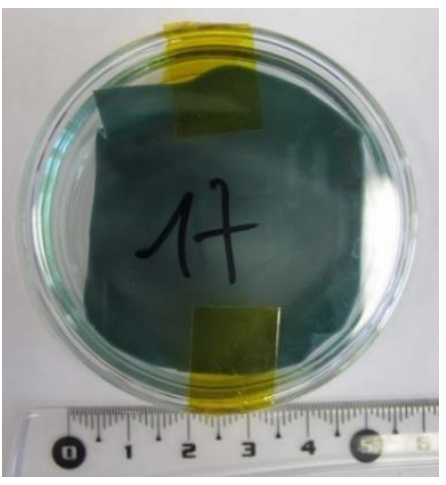

I First-step irradiation

- Irradiations using open pillboxes

=> Ageing mechanism determination

- Second-step irradiation

- In closed ampoules under controlled atmosphere

- Masses estimated to attain

- Final hydrogen content $<1 \%$ vol to avoid readdition

- Final oxygen content $>10 \%$ vol to ensure homogeneous oxidative conditions

=> Gases quantification at different doses

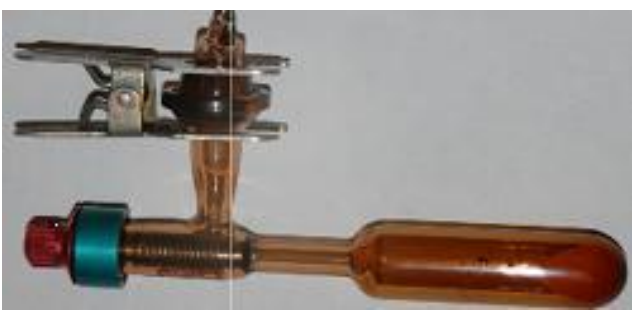




\section{Gases evolution as a function of dose}
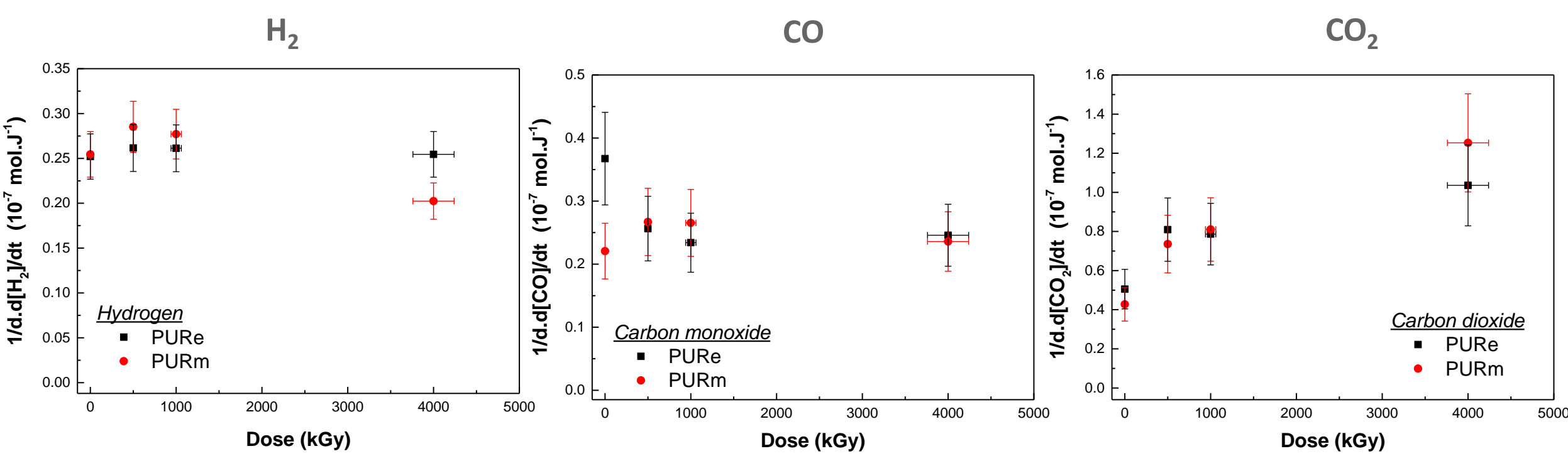

- Representation in mol. $\mathrm{J}^{-1}$ of energy deposited in the polymeric resin

- PURe: $100 \%{ }_{w t}$ of the material vs PURm: $88.9 \%_{w t}$ of the industrial material - No relevant influence of charges and additives on the gases evolved

I. Dose effect up to 4000 kGy:

- No dose effect on $\mathrm{H}_{2}$ and $\mathrm{CO}$ release

- $\mathrm{CO}_{2}$ increases

- Formation of carboxylic acids under radio-oxidation [1]

- These carboxylic acids are then degraded when dose further increases 


\section{cea den Gases evolution as a function of dose}
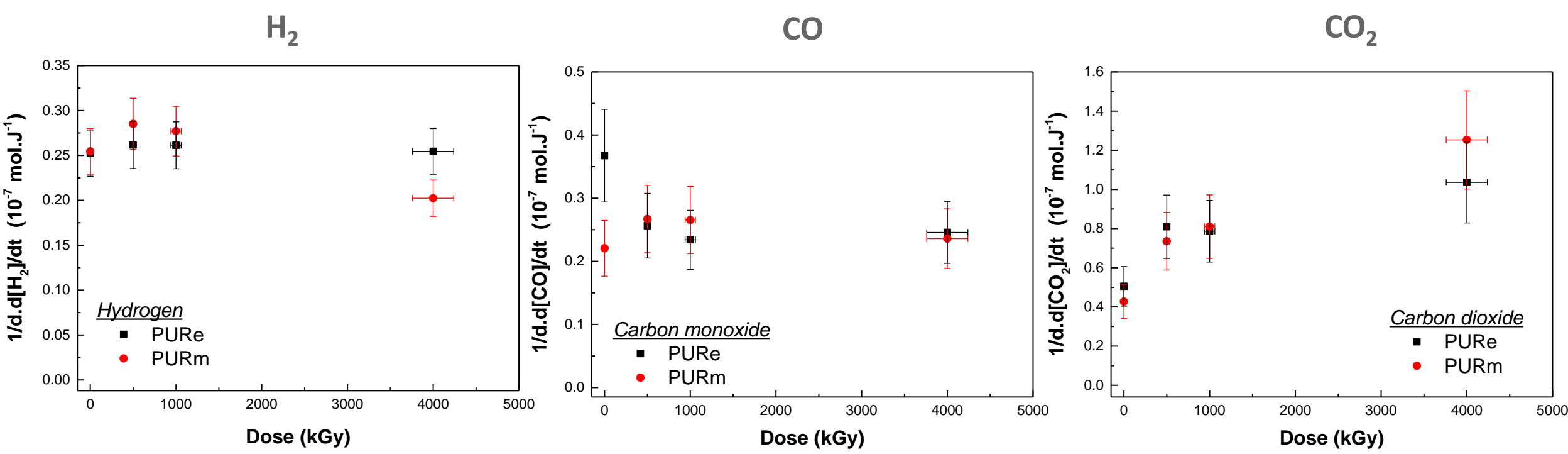

- Both PUR relatively stable under irradiation

- Compared to other polymers found in IL-LLW like PE $-\mathrm{G}\left(\mathrm{H}_{2}\right)_{\mathrm{PE}} \approx 3.5 \cdot 10^{-7} \mathrm{~mol} / \mathrm{J} \mathrm{vs} \mathrm{G}\left(\mathrm{H}_{2}\right)_{\mathrm{PUR}} \approx 0.25 \cdot 10^{-7} \mathrm{~mol} / \mathrm{J}$<smiles>CCCc1ccc(CC=Cc2ccc(CC)cc2)cc1</smiles>

- Stability partly due to

- Aromatic rings from the hard segments [2-4]

- Esters from the soft segments... [5]<smiles>O=C(CCCCC(=O)OCCCCO)OCCO</smiles>
$=>$ Both behave as energy and/or radical scavengers

[2] Dannoux et al., J. Polym. Sci. Part B : Polym. Phys. 46 (2008), 861

[3] Ferry et al., J. Phys. Chem. B 117 (2013), 14497

[4] Chang \& LaVerne, . Phys. Chem. B 104 (2000), 10557

[5] Ferry et al., Nucl. Instrum. Methods Phys. Res., Sect. B 334 (2014), 69 


\section{ceaden}

\section{Materials evolution as a function of dose}

Visual evolution and ultimate analyses

\section{PURe}

Non-irradiated 500 kGy
1000 kGy 4000 kGy

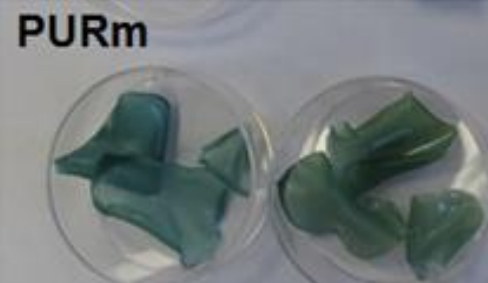

Non-irradiated 500 kGy

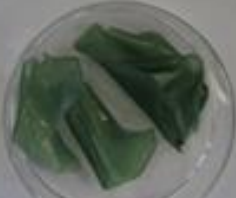

1000 kGy

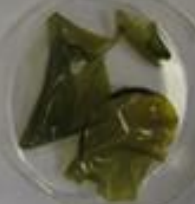

4000 kGy
Radio-oxidized polymer

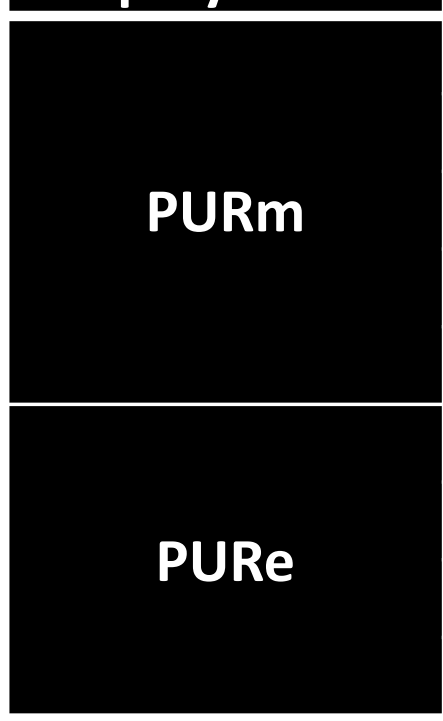

Mean dose (kGy)

0

500

1000

4000

10000

0

500

1000

4000

\section{Organic elements analysis ( $\left.\%_{\text {weight }}\right)$}

C

56.8

56.7

56.5

55.3

53.8

61.9

61.4

61.3

60.0
$\mathrm{H}$

6.7

6.7

6.4

6.2

7.3

7.3

7.2

7.1
6.6
0 24.3

24.3

24.6

26.4

28.2

28.1

28.8

28.7

30.3
$\mathrm{N}$

3.2

3.2

3.2

3.2 3.0

2.5

2.5

2.5

2.5
$C \& H \searrow$

- Gas release $\left(\mathrm{CO}, \mathrm{H}_{2} \ldots\right)$

- 0 ス

- New bonds formation $(-\mathrm{OH},-\mathrm{OOH}, \mathrm{C}=\mathrm{O} \ldots)[6]$

I. $\mathrm{N} \rightarrow$

- No urethane bond scission

- Confirmed by the absence of NOx gases 
PURe

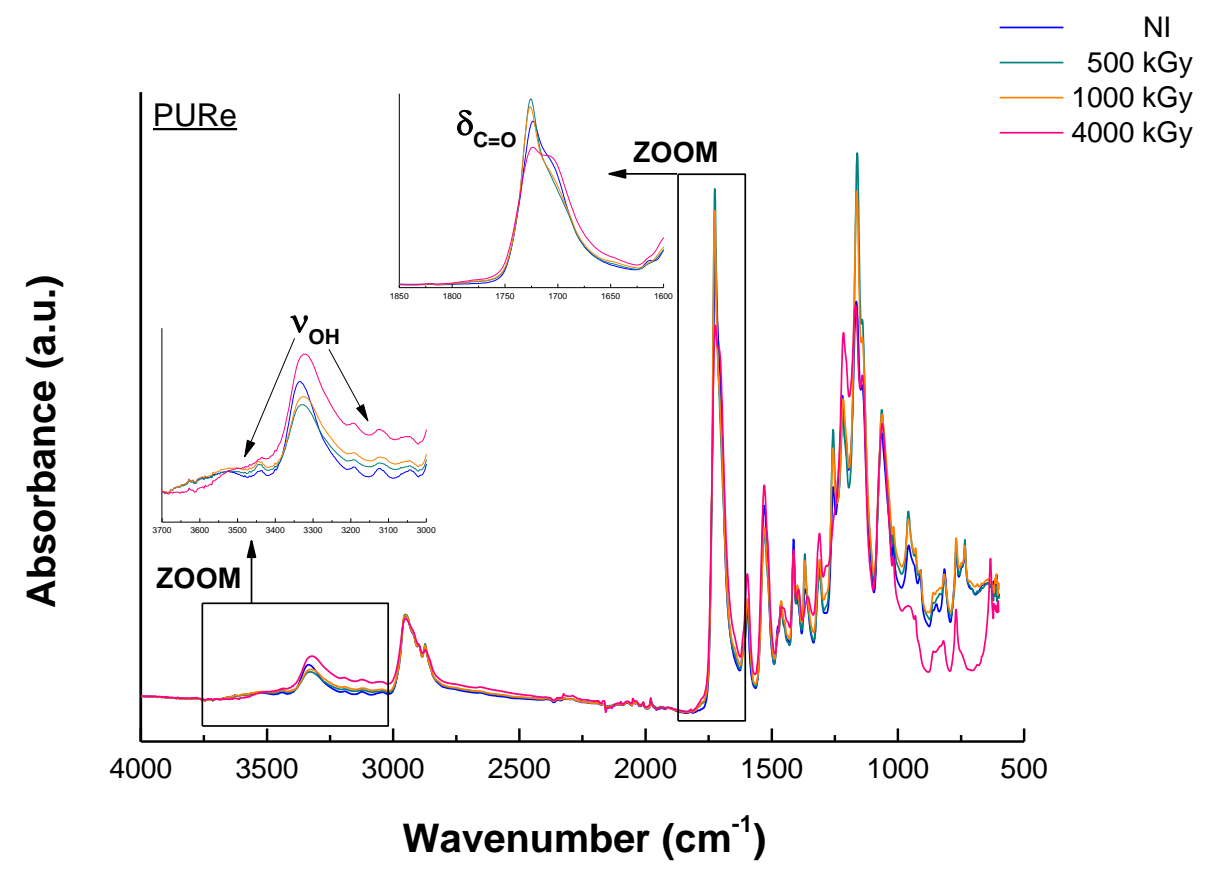

PURm

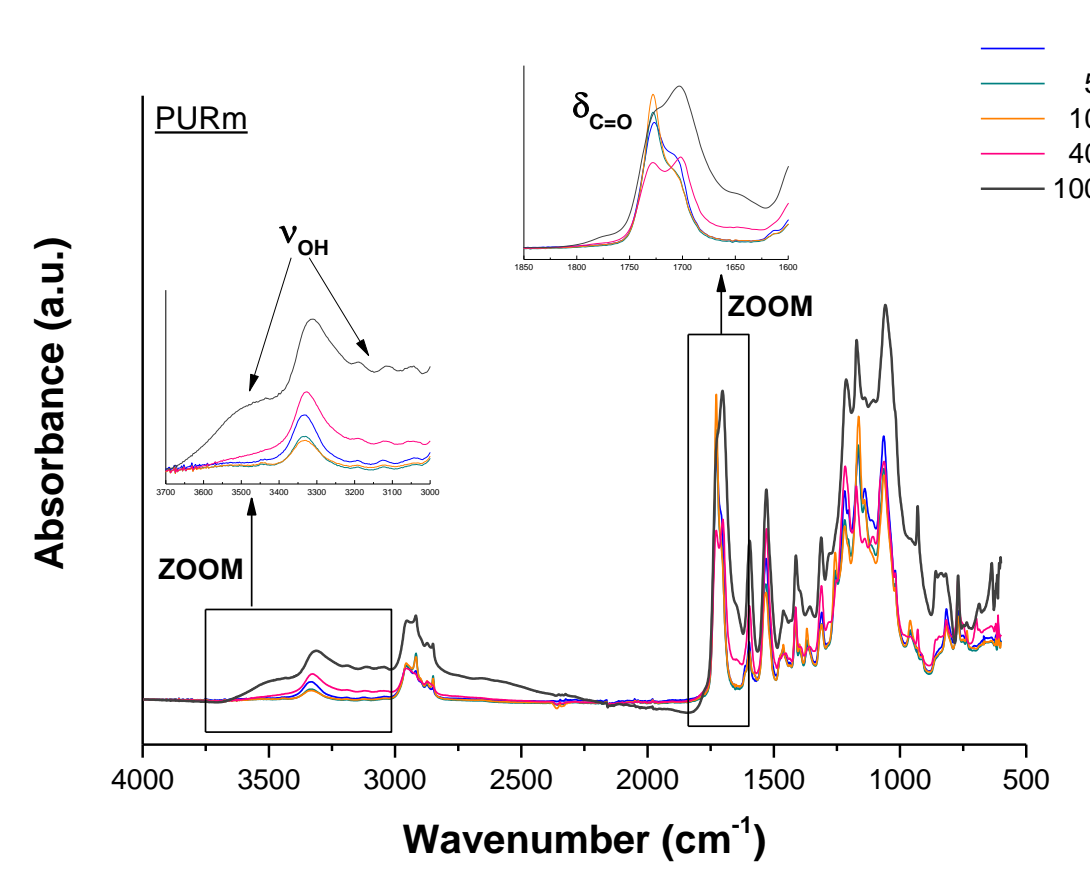

E Formation of new bonds in both PUR up to $4000 \mathrm{kGy}$

- 3600-3000 $\mathrm{cm}^{-1}: \mathrm{v}_{\mathrm{OH}}$

- $1800-1650 \mathrm{~cm}^{-1}: \delta_{\mathrm{C}=0}$ 


\section{Infrared spectroscopy (FTIR)}

Particular case : PURm at 10000 kGy

- Shoulder at $1780 \mathrm{~cm}^{-1}$

- Could be lactones [7]

- Band at $1640 \mathrm{~cm}^{-1}$

- $\mathrm{C}=\mathrm{C}$ double bonds

- Surprising under homogeneous oxidative conditions

- Maybe conjugated bonds (by correlation with the visual evolution, i.e. yellowing of the irradiated polymers)

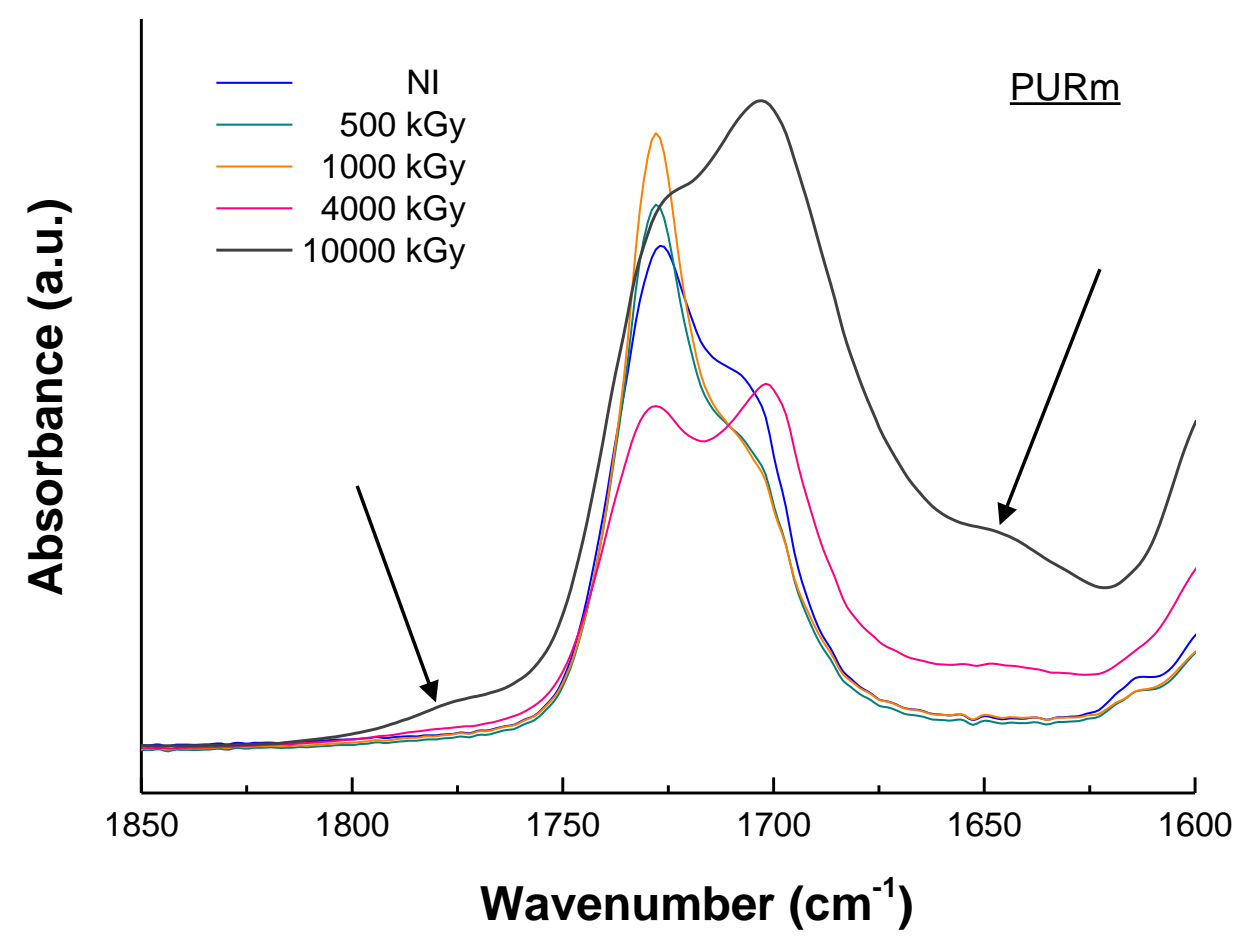

All infrared band attributions (containing carbon) confirmed by C-1s XPS analyses 
1 Soluble fraction in THF followed as a function of dose for both polymers

- Non-irradiated polymers

- Totally soluble

- Up to about 500 kGy

- Ratio scission/crosslinking $\searrow$

- By about 500 kGy

- Ratio scission/crosslinking 7

- Total solubility attained again at $\approx 4000 \mathrm{kGy}$ for PURe and at doses higher than $10000 \mathrm{kGy}$ for PURm

- Evolution of the ageing mechanism as a function of dose

- Evaluation of the polymers behavior at these high doses

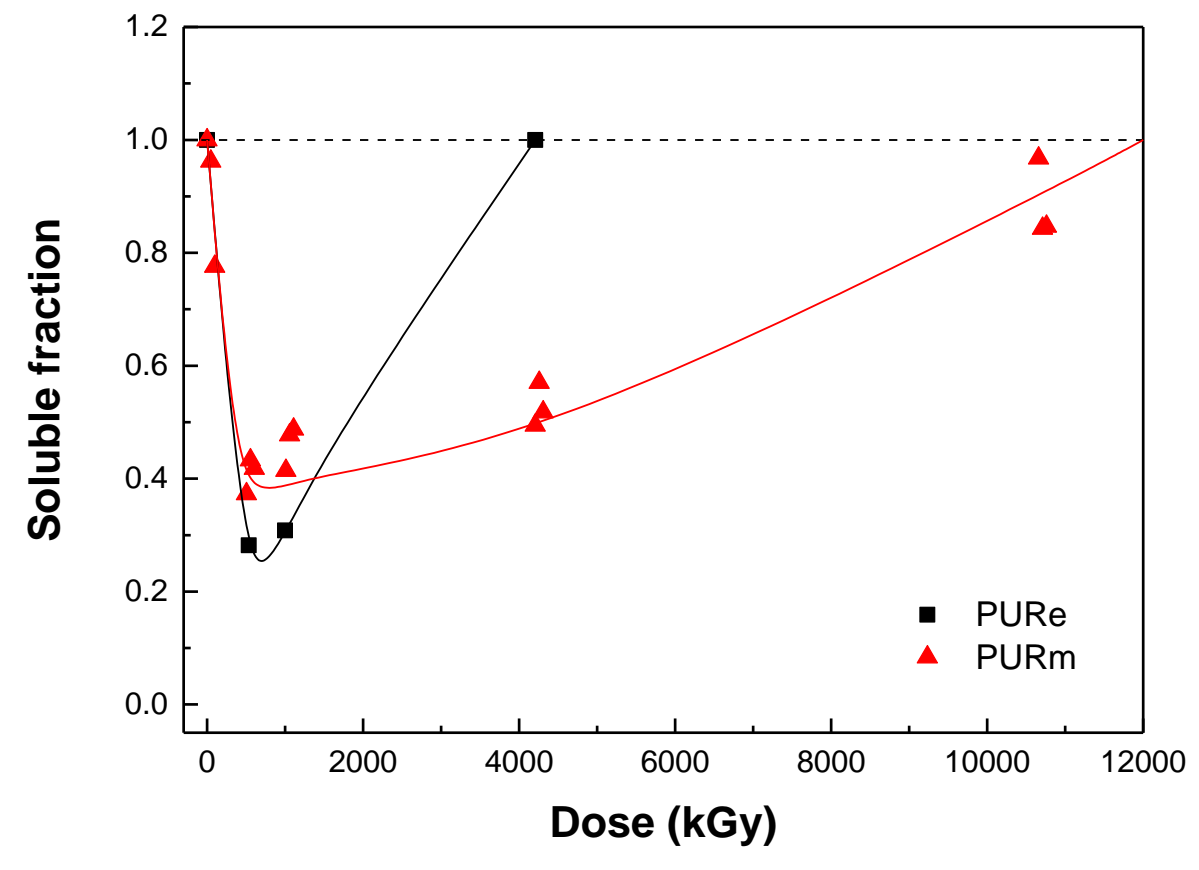

- First evidence of a difference between the two PUR 
Attempt to identify the molecules trapped in the polymer

- Extraction in methanol

- ESI-MS of the extracted molecules

How<smiles>CC(=O)CCCCC(=O)OCCCCOC(C)(C)C</smiles>

$\left[0{ }^{-1}\right.$

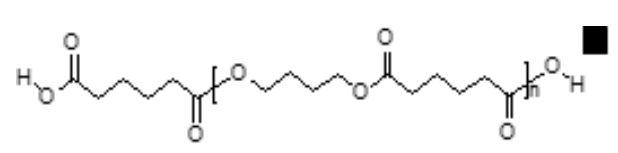

$\left[\begin{array}{llll}0 & 0\end{array}\right]$

- Identification of oligomers from soft segments
EF-161129-PURE 1 METHANOES+ 110 (2.049) Cm (53:114)

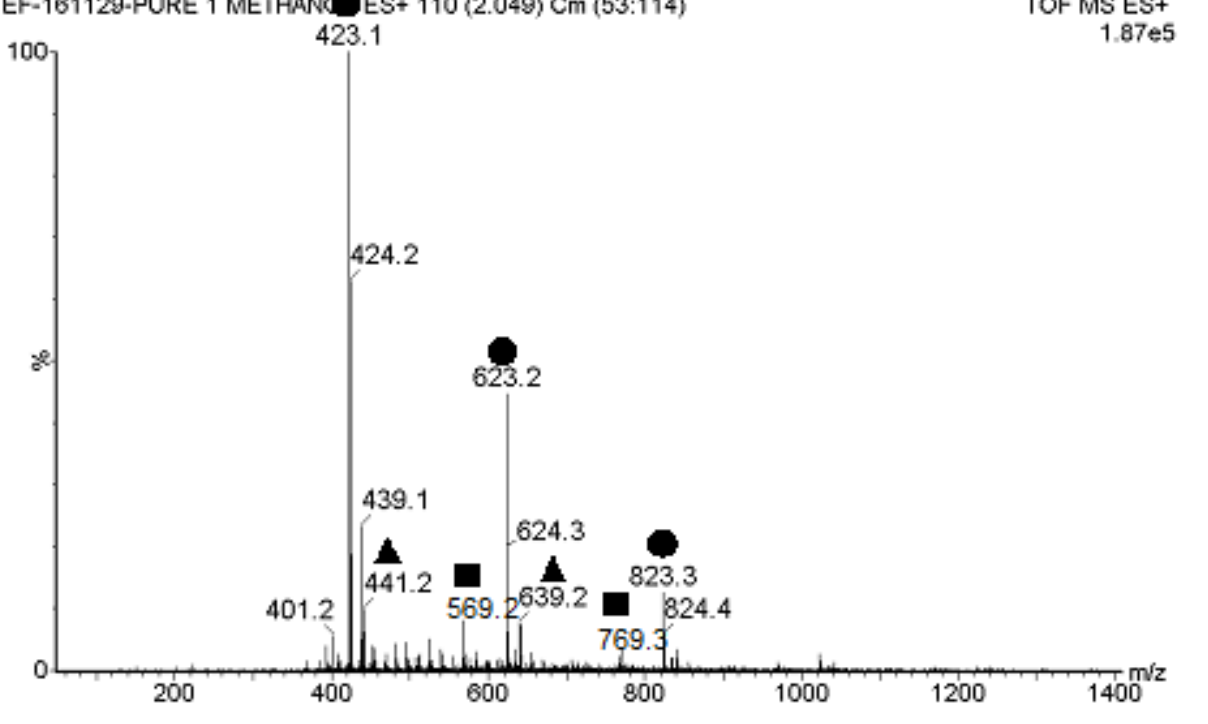

EF-161129-PURE 1 METHANOL ES- 5 p.936) Cm (49:106)

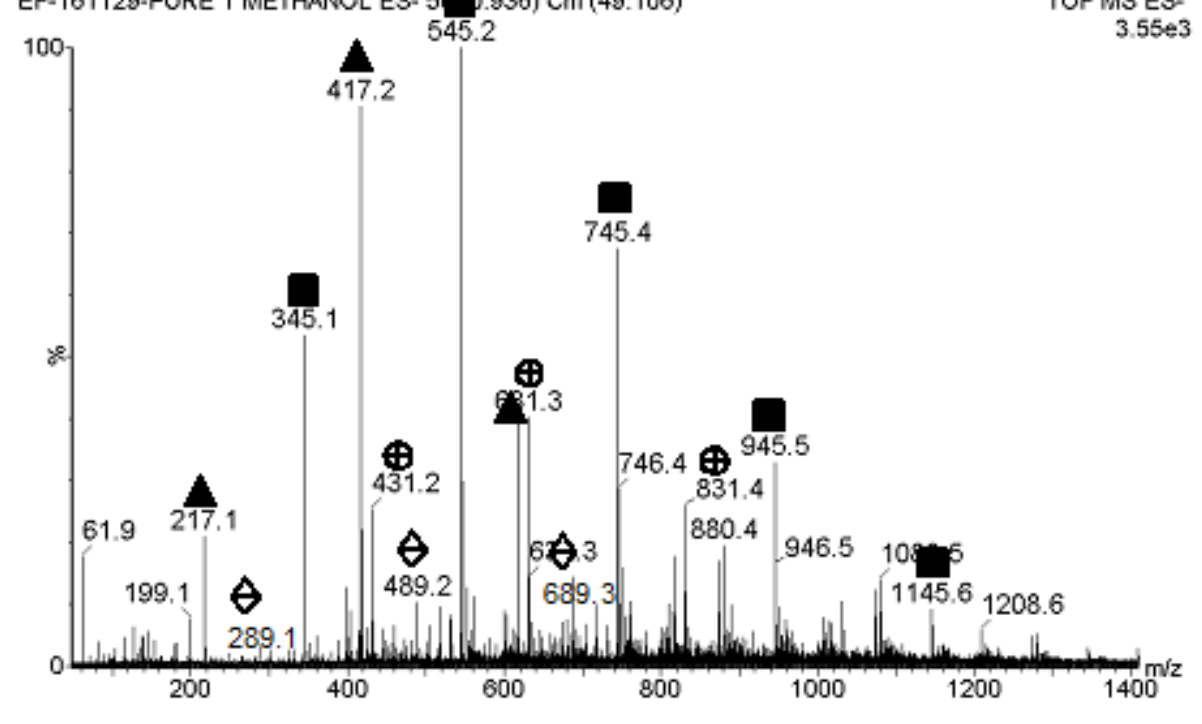




\section{Low molecular mass trapped molecules identification}

\section{\begin{tabular}{|l|l} 
Kind of molecules & Example of molecules
\end{tabular}}

Oligomers

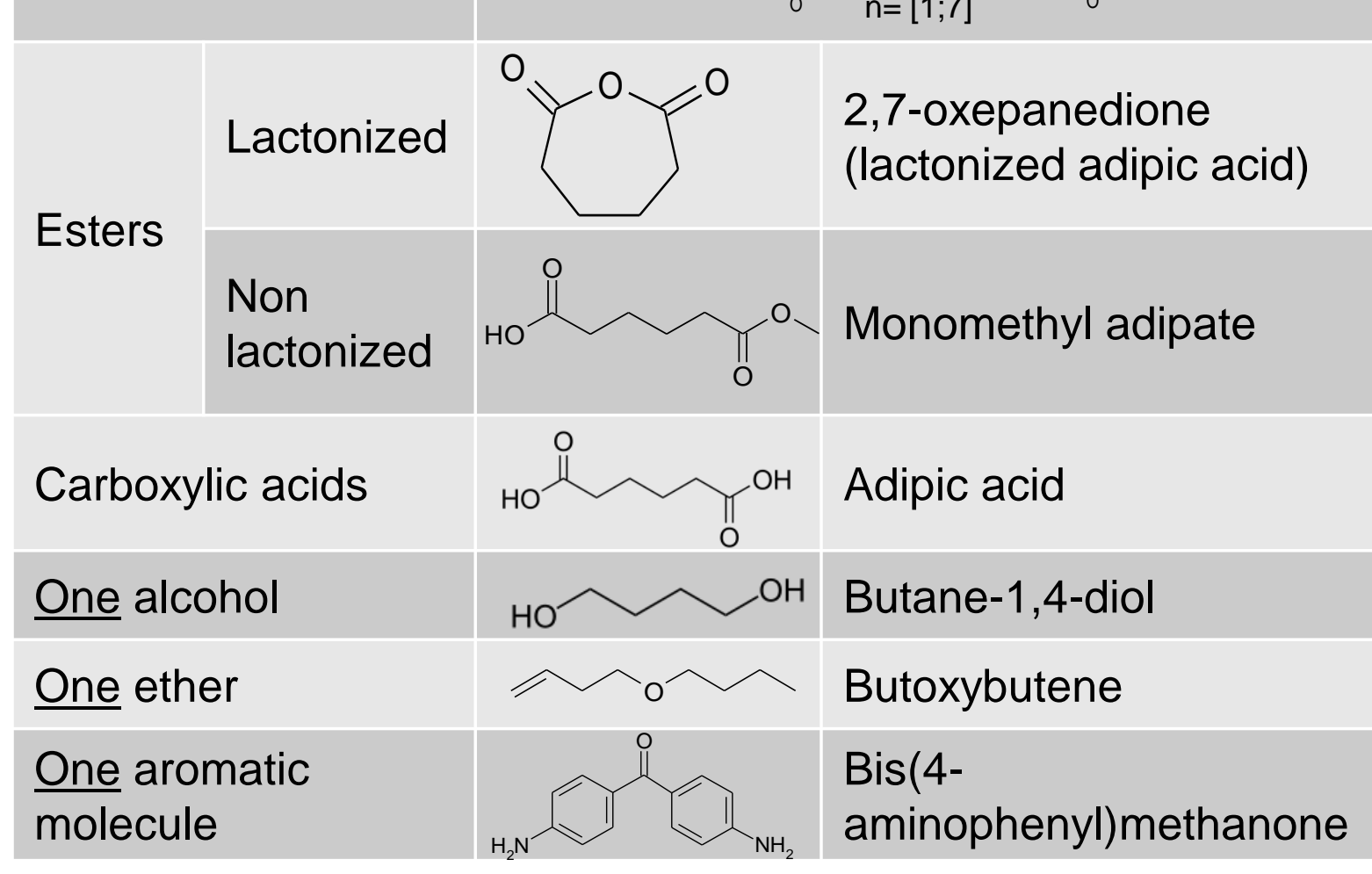

I Lactones and double bonds

- Confirmation of their presence (FTIR spectra analysis)

- Aromatic molecule

- Observed only from PURm radio-oxidized at 10000 kGy

- First and only evidence of the hard segments decomposition 
Eadio-oxidation of PUR: degradation mechanisms up to $10 \mathrm{MGy}$ - Dose effect moderated (energy and/or radical scavengers)

E For pure resin (PURe) as for industrial material (PURm)

- Quantification of the main gases evolved

$-\mathrm{H}_{2}$ and $\mathrm{CO} \rightarrow$ and $\mathrm{CO}_{2} \lambda$

- New bonds in the polymers

- Lactones, ketones, alcohols, hydroperoxides... but also double bonds

- Low molecular mass molecules trapped

- Oligomers, adipic acid... mainly issued from soft segments

- Degradation mechanism of the aromatic polyesterurethanes under radiooxidation

- Ester bonds scissions

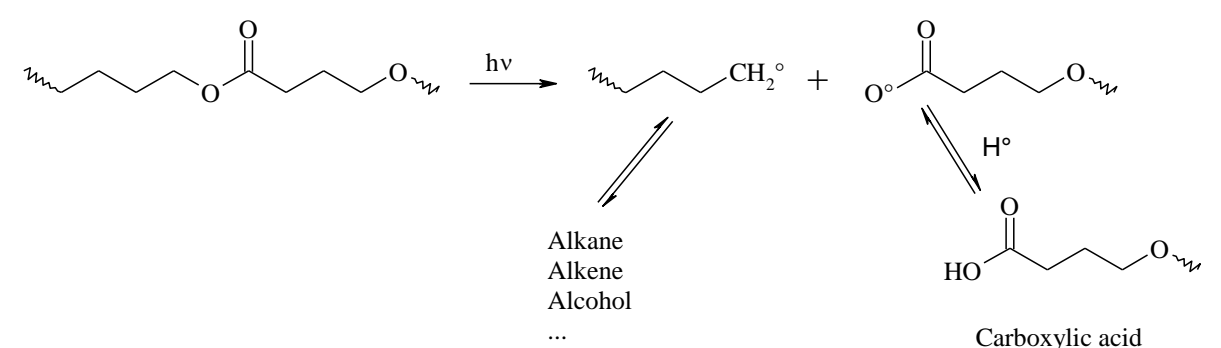


- Charges and additives presence effect

- Separation of the effect of radio-oxidation on the resin and on the other components of an industrial polymer

- Degradation mechanism for one polymer family

- No irradiation of all materials

- Verification with few experiments

- Quantification of the radiation chemical yields of gases - Integration into a simulation program

- All the main polymer families encountered in IL-LLW studied -Chlorinated polymers, polyolefins... 


\section{Thank you for your attention}

\section{Acknowledgements}

- S. Rouif (IONISOS), P. Le Tutour (LABRA) \& V. Labed (GAMMATEC)

for their helpful collaboration during irradiations

- A. Geysen \& J. Goldberg (Lubrizol) for providing PURe

- S. Legand, D. Lebeau, J.L. Roujou, D. Durand, V. Dauvois \& S. Esnouf (LRMO) for their assistance during experiments 